\title{
Effective Utilization of quarry waste and industrial waste as partial replacement of fine aggregates in concrete to resist acid attack
}

\author{
Priyanka $\mathrm{M}^{1}$, Sakthieswaran $\mathrm{N}^{2}$ \\ ${ }^{1}$ Research Scholar, Department of Civil Engineering, Anna University, Regional Campus, Tirunelveli, Tami Nadu, India. \\ 1mpriyanka2091@gmail.com \\ ${ }^{2}$ Assistant Professor, Department of Civil Engineering, Anna University, Regional Campus, Tirunelveli, Tami Nadu, India. \\ ²sakthistructrichy@gmail.com
}

\begin{abstract}
The aim of this study is to observe the concrete resistance towards acid attack. This is studied on M40 grade concrete, in which $5 \%$ by weight of binder is replaced with metakaolin and fine aggregate is replaced partially with the range of 5 to $20 \%$ by marble sludge powder and green sand simultaneously. Four different mixes other than control mix is taken for this study. The $100 \mathrm{~mm}$ cubes are casted, cured and average compressive strength is compared with conventional concrete and those cured under two different acids. The two different acids taken for this study are Hydrochloric Acid and Sulphuric Acid. The average percentage loss of weight and average compressive strength of cubes before and after two different acids for all the mixes are investigated. From the experimental results, it is inferred that the control mix when cured under both $1 \%$ concentrated $\mathrm{HCl}$ and $\mathrm{H}_{2} \mathrm{SO}_{4}$ solutions showed a high loss in weight comparing with modified concrete. The increase in marble powder and green sand upto $10 \%$ by weight of fine aggregate gives high reduction in loss of weight. The mix with $10 \%$ marble powder and green sand offered comparatively better solutions insisting the concrete modified with the same can be recommended for making good and acid resisting concrete.
\end{abstract}

\section{Keywords}

Metakaolin, Green sand, Marble powder, Hydrochloric, Sulphuric acid, loss in weight, compressive strength

\section{INTRODUCTION}

The constituents together to make homogenous concrete will have alkaline property. The consistency of the cement paste gets deteriorated when it is subjected to acidic environment. Concrete degrades by the concentration of acids and the porous nature of cement paste. Concrete is very aggressive towards nitric, sulphuric and hydrochloric whereas less damaging when attacked by phosphoric acid. Especially sulphuric acid is the most destructive acids. Water itself an important factor for chemical attack. Spilling, dumping industrial-chemical wastes and washed away concrete in sewer pipes are some forms of concrete attacked by acids. These sequential invasion leads to heavy damage or costs high repair or to alter the whole structure. Polyethylene terephthalate (PET) can be used upto $15 \%$ as an alternative aggregate to resist suphuric attack by showing reduction in loss of weight and better strength of concrete [1]. Disposing marble sludge powder is found to be effective such that it reduces permeability. In addition, this also protects the environment from dumpsites. This marble sludge powder when used in concrete increases workability with reduced permeability thus resistant to acid attack. Marble sludge powder is a by-product from shaping. It is very fine particles of about $90 \%$ of the account. $8 \%$ marble powder used as admixture in concrete gives improved mechanical properties, durability and results in impermeable concrete [3]. Permeability of green concrete is reduced when modified with quarry dust and marble sludge powder [4]. Metakaolin is a pure form of calcinated clay under high temperature of about $800{ }^{\circ} \mathrm{C}$ and then ground to 1.5 to 2 micrometers. Attention of metakaolin has become very popular. Using optimum of $7.5 \%$ by weight of cement high reactivity metakaolin increases strength resistance to sulphate attack of concrete [5]. Concrete resists acid attack when modified with $15 \%$ metakaolin and $20 \%$ silica fume replaced for weight of binder [6]. Concrete modified with $10 \%$ by weight of binder offered better resistance to hydrochloric acid [7]. The optimum use of $15 \%$ by weight of binder replaced with metakaolin offered better resistance to acid attacks [8]. The use of HRM at 5 to $12 \%$ can be used for increasing resistance against chloride ion penetration and high levels of 10 to $20 \%$ for reducing expansion risk from alkali-silicate reactivity [9]. Disposing of foundry sand, an industrial by-product is a severe problem in this scenario. To overcome this with solution, recycling or reuse of these by-products as alternative for construction materials this will be sustainable disposal to our environment. This foundry sand is a by-product of non-ferrous and ferrous hardened cast metals. It has higher silica quantity, coated with thin film of burnt carbon, residual binder and dust [10-12]. Green sand is finer than regular sand. The use of green sand decreases the workability $[10,13]$ and compressive strength when used with nominal coarse aggregates [10]. Concrete expands due to increase in volume of solids. Strength at 56 days and 90 days decreases when the concrete modified with hemp and foundry sand [2]. A systematic loss in workability of fresh concrete with increase in foundry sand content and increase in water absorption with increase in green sand content in concrete mix. It is recommended to use higher amount of super-plasticizers when increased amount of foundry sand is replaced for natural fine aggregates with same water-cement ratios to keep up the workability at a good standard. It is also told that plain mortar with $0.5 \mathrm{w} / \mathrm{c}$ ratio requires $0.5 \%$ of cement by weight in addition whereas, it is about $1.8 \%$ of cement needed when green sand is used [14,19]. When $15 \%$ aggregate is replaced with green sand, mechanical properties are increased and as well produces impermeable concrete with increase in density. This results in reduction of chloride penetration. Presence of green sand with $75 \% \mathrm{M}$-sand shows greater strength in concrete [18]. The weight loss due to acid attack was considerable for the concrete modified with $30 \%$ WFS with $0.5 \%$ carbon fibre. The high quality silica present in WFS offered better resistance to acids [19]. In this study, the concrete was modified for its partial amount of fine aggregate by marble sludge powder and green sand to improve the performance against acid attack and $5 \%$ by weight of binder is replaced by metakaolin to enhance the pozzolanic activity throughout the study. 


\section{MATERIALS AND MIX DESIGN}

The Ordianry Portland cement (OPC 43 grade) conforming to IS8112 - 2013 is used throughout this study. Metakaolin and greensand conforming to IS8112 -2013 and IS1918-1966 is used for this investigation. The chemical composition for cement, metakaolin, marble powder and green sand is shown in Table 1. Marble powder and greensand is used as partial replacement of fine aggregates and metakaolin is replaced for $5 \%$ of binder. The physical properties of cement, metakaolin, marble powder and greensand are given in Table 2. The mix design for M40 grade is done according to IS 10262 - 2009. Water to binder ratio is 0.4 and the mix ratio and mix quantity is given in Table 3.The proportions of various percentage replacement of fine aggregate is shown in Table 4.

Table 1. Chemical Composition of Cement, Metakaolin, Marble powder and Green sand.

\begin{tabular}{|c|c|c|c|c|}
\hline Chemical Composition (\%) & Cement & Metakaolin & Marble powder & Green sand \\
\hline $\mathrm{SiO}_{2}$ & 22 & 52 & 0.67 & 87.91 \\
\hline $\mathrm{Al}_{2} \mathrm{O}_{3}$ & 5 & 43 & 0.12 & 4.70 \\
\hline $\mathrm{Fe}_{2} \mathrm{O}_{3}$ & 0.5 & 2.1 & 0.08 & 0.94 \\
\hline $\mathrm{MgO}$ & 3.5 & 0.03 & 0.59 & 0.30 \\
\hline $\mathrm{Na}_{2} \mathrm{O}$ & 1 & 0.01 & 0.14 & 0.19 \\
\hline $\mathrm{K}_{2} \mathrm{O}$ & 1 & 0.1 & - & 0.25 \\
\hline $\mathrm{CaO}$ & 65 & 0.05 & 54.43 & 0.14 \\
\hline $\mathrm{SO}_{3}$ & 2 & - & - & 0.09 \\
\hline $\mathrm{SO}_{4}$ & - & 0.3 & - & - \\
\hline $\mathrm{TiO}_{2}$ & - & 2.06 & - & 0.15 \\
\hline $\mathrm{T}_{2} \mathrm{O}_{5}$ & - & 0.05 & - & - \\
\hline $\mathrm{P}_{2} \mathrm{O}_{5}$ & - & 0.05 & - & - \\
\hline L.O.I & - & 0.3 & 43.4 & 5.15 \\
\hline $\mathrm{Mn}_{2} \mathrm{O}_{3}$ & - & - & - & 0.02 \\
\hline $\mathrm{CuO}$ & - & - & - & - \\
\hline SulphideSulphur & - & - & - & - \\
\hline Insoluble Residue & - & - & - & - \\
\hline Chloride & $\bar{x}$ & - & - & - \\
\hline+2 & - & - & - & 0.03 \\
\hline
\end{tabular}

Table 2. Physical propertiesof Cement, Metakaolin, Marble powder and Green sand.

\begin{tabular}{|c|c|c|c|c|}
\hline Physical properties & Cement & Metakaolin & Marble powder & Green sand \\
\hline Initial setting time (minutes) & 39 mins & & & \\
\hline Final setting time (minutes) & 220 mins & & & \\
\hline Specific gravity & 3.15 & 2.60 & 2.62 & 2.6 \\
\hline Moisture content & & & $1.5 \%$ & \\
\hline Water absorption & & & $2 \%$ & \\
\hline Bulk density(g/cm $\left.{ }^{3}\right)$ & & $0.3-0.4$ & 1480 & \\
\hline Grading & & & Zone II & \\
\hline Fineness modulus & & & 2.68 & \\
\hline Physical form & Powder & Powder & Powder & Powder \\
\hline
\end{tabular}


Table 3. Mix Design and Proportion

\begin{tabular}{|c|c|c|c|c|}
\hline Design Mix & Water & Cement & Fine Aggregate & Coarse Aggregate \\
\hline By Volume $\left(\mathrm{kg} / \mathrm{m}^{3}\right)$ & 164 & 350 & 729 & 1250 \\
\hline By ratio & 0.4 & 1 & 2.08 & 3.57 \\
\hline
\end{tabular}

Table 4. Mix Proportions with percentage replacement for cement and sand

\begin{tabular}{|c|c|c|c|c|c|}
\hline \multirow{2}{*}{$\begin{array}{c}\text { Mix } \\
\text { ID }\end{array}$} & \multicolumn{2}{|c|}{ Binder } & \multicolumn{3}{c|}{ Fine Aggregate } \\
\cline { 2 - 6 } & Cement & Metakaolin & Sand & Marble powder & Green sand \\
\hline M0 & 100 & $\%$ & $\%$ & $\%$ & 0 \\
\hline M1 & 95 & 0 & 100 & 5 & 5 \\
\hline M2 & 95 & 5 & 90 & 10 & 10 \\
\hline M3 & 95 & 5 & 80 & 15 & 15 \\
\hline M4 & 95 & 5 & 70 & 20 & 20 \\
\hline
\end{tabular}

\section{TESTING PROCEDURE}

\subsection{Sulphuric Acid attack Test}

The concrete is tested for acid attack as per standard procedure,

1. Concrete cubes of $100 \mathrm{~mm}$ are casted. The specimens are demoulded after $24 \mathrm{hrs}$ and cured in fresh water for $28 \mathrm{days}$

2. After 28 days, each specimen is weighed.

3. The weighed specimens are then placed in plastic tubs. Then the $1 \%$ concentrated solutions of sulphuric acid.

4. The specimens should be arranged such that the clearway above the specimens should not be less than $30 \mathrm{~mm}$. Every day the solution was checked for the clearance.

5. After 28 days, the specimens are taken out, brushed with soft nylon brushes and washed with tap water ensuring that the loose particles on the surface of the specimens are removed.

6. The specimens were weighed and observed for the average percentage of loss of weight and compressive strengths were calculated by,

$\%$ loss of weight $=\frac{\mathrm{W} 1-\mathrm{W} 2}{\mathrm{~W} 1} \times 100$

Where,

W1 - Weight of specimen after 28 days of water curing.

W2 - Weight of specimen after 28 days of sulphuric acid curing.

\subsection{Hydrochloric Acid attack Test}

The concrete is tested for acid attack as per standard procedure,

1. Concrete cubes of $100 \mathrm{~mm}$ are casted. The specimens are demoulded after $24 \mathrm{hrs}$ and cured in fresh water for $28 \mathrm{days}$.

2. After 28 days, each dried specimen is weighed.

3. The weighed specimens are then placed in plastic tubs. Then the $1 \%$ concentrated solutions of Hydrochloric acid.

4. The specimens should be arranged such that the clearway above the specimens should not be less than $30 \mathrm{~mm}$. Every day the solution was checked for the clearance.

5. After 28 days, the specimens are taken out, brushed with soft nylon brushes and washed with tap water ensuring that the loose particles on the surface of the specimens are removed.

6. The specimens were weighed and observed for the average percentage of loss of weight and compressive strengths were calculated by,

$\%$ loss of weight $=\frac{\mathrm{W} 1-\mathrm{W} 2}{\mathrm{~W} 1} \times 100$

Where, 
W1 - Weight of specimen after 28 days of water curing.

W2 - Weight of specimen after 28 days of hydrochloric acid curing.

\section{RESULTS AND DISCUSSIONS}

\subsection{Loss in weight of concrete against acidic environment}

Table 5 and Table 6 show the responses by loss in weight for the two acidic environments. This loss in weight is due to the chemical reaction between the constituents in concrete matrix and acids thus forming pores in the specimen. The percentage loss in weight decreases with increase in partial replacement of green sand and marble powder. The control concrete showed great loss in weight after the attack of acids. This shows that the concrete modified with marble powder and green sand reduces loss in weight when subjected to both hydrochloric and suplhuric acids. The improvement in reduction in weight of modified concrete mixes $\mathrm{M} 1, \mathrm{M} 2, \mathrm{M} 3$ and $\mathrm{M} 4$ when exposed to $\mathrm{HCl}$ solution are observed as $18 \%$, $53.6 \%, 55.6 \%$ and $61 \%$ better as that of control concrete exposed to $\mathrm{HCl}$. Similarly, the loss in weight of modified concrete mixes M1, M2, M3 and M4 were 3.4\%, 4.04\%, 29.23\% and 41.5\% lower than the control mix M0 when exposed to $\mathrm{H}_{2} \mathrm{SO}_{4}$ solution. The control concrete under $\mathrm{H}_{2} \mathrm{SO}_{4}$ lost $18.8 \%$ more than the weight lost when subjected to $\mathrm{HCl}$ solution. This infers that the control concrete gets more impact when subjected to Sulphuric environment. It is also inferred that the percentage loss in weight due to $\mathrm{H}_{2} \mathrm{SO}_{4}$ is $29.65 \%, 59.67 \%, 47.75 \%$ and $44.11 \%$ greater than the percentage loss in weight due to $\mathrm{HCl}$ for modified concrete $\mathrm{M} 1, \mathrm{M} 2, \mathrm{M} 3$ and $\mathrm{M} 4$ respectively.

\subsection{Average Compressive Strength of concrete exposed to acidic environment}

Table 5 and Table 6 show the responses in average compressive strength for the two acidic environments. Obvious to loss in weight, the average compressive strength of concrete is observed. This is indirectly proportional with loss in weight. It is reviewed from literature that to enhance pozzolanic actions, use of metakaolin can be raised to $7.5 \%$ by weight of binder to resist sulphuric acid.The average compressive strength of concrete decreases with increase in weight loss of concrete. The compressive strength of $\mathrm{HCl}$ and $\mathrm{H}_{2} \mathrm{SO}_{4}$ acid cured control concrete is $2.9 \%$ and $16.26 \%$ less than that of water cured specimens respectively. The maximum average compressive strength was observed for the mix $\mathrm{M} 2$ which incorporates $10 \%$ marble and greensand as replacement for fine aggregate. The reduction in strength of mix M2 under $\mathrm{HCl}$ and $\mathrm{H}_{2} \mathrm{SO}_{4}$ curing is observed as $1.7 \%$ and $10.7 \%$ when compared with water cured specimens. The water cured modified concrete mix shows better average compressive strength than $\mathrm{HCl}$ and $\mathrm{H}_{2} \mathrm{SO}_{4}$ cured specimens. It is also inferred that the compressive strength increase with increase in replacing fine aggregate upto $20 \%$ and decreases with increase in marble powder and green sand beyond $20 \%$ of fine aggregate replaced.

Table 5. Acid Attack - Hydrochloric acid Solution

\begin{tabular}{|c|c|c|c|}
\hline $\begin{array}{l}\text { MIX } \\
\text { ID }\end{array}$ & $\begin{array}{c}\text { Percentage loss in } \\
\text { weight after acid curing }\end{array}$ & $\begin{array}{l}\text { Compressive Strength } \\
\text { before acid attack }\left(\mathrm{N} / \mathrm{mm}^{2}\right)\end{array}$ & $\begin{array}{l}\text { Compressive Strength } \\
\text { after acid attack }\left(\mathrm{N} / \mathrm{mm}^{2}\right)\end{array}$ \\
\hline MO & 0.97 & 42.25 & 41.02 \\
\hline M1 & 0.79 & 43.61 & 42.06 \\
\hline M2 & 0.45 & 43.96 & 43.21 \\
\hline M3 & 0.43 & 28.36 & 26.04 \\
\hline M4 & 0.38 & 19.17 & 15.88 \\
\hline
\end{tabular}

Table 6. Acid Attack - Sulphuric acid Solution

\begin{tabular}{|c|c|c|c|}
\hline $\begin{array}{l}\text { MIX } \\
\text { ID }\end{array}$ & $\begin{array}{c}\text { Percentage loss in } \\
\text { weight after acid curing }\end{array}$ & $\begin{array}{c}\text { Compressive Strength } \\
\text { before acid attack }\left(\mathrm{N} / \mathrm{mm}^{2}\right)\end{array}$ & $\begin{array}{l}\text { Compressive Strength } \\
\text { after acid attack }\left(\mathrm{N} / \mathrm{mm}^{2}\right)\end{array}$ \\
\hline MO & 1.163 & 42.25 & 35.38 \\
\hline M1 & 1.123 & 43.61 & 37.64 \\
\hline M2 & 1.116 & 43.96 & 39.24 \\
\hline M3 & 0.823 & 28.36 & 26.88 \\
\hline M4 & 0.68 & 19.17 & 18.66 \\
\hline
\end{tabular}

\section{CONCLUSION}

It is concluded from this study that,

- The use of metakaolin, green sand and marble powder in the conventional concrete makes reduction in loss of weight.

- The increase in marble powder and green sand upto $10 \%$ by weight of fine aggregate gives high reduction in loss of weight.

- The average compressive strength is high for the concrete which replaces $20 \%$ of fine aggregate with marble powder and green sand. 


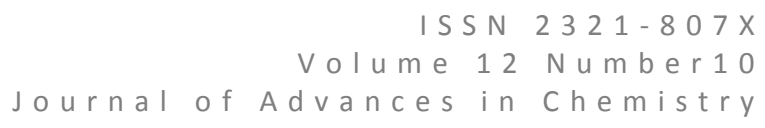

- This modified concrete M2 gives better resistance when attacked by hydrochloric and sulphuric acids recommending for acid resistance and constructable concrete.

\section{REFERENCES}

1. Janfeshan Araghi, H., Nikbin, I.M., Rahimi Reskati, S., Rahmani, E., Allahyari, H. 2015. An experimental investigation on the erosion resistance of concrete containing various PET particles percentages against sulfuric acid attack. Construction and Building Materials. 77, 461-471.

2. Sivasubramanian, R., Rajalingam, M., Sunilaa George. 2015. Study of Chemical Attack using Green Materials. International Journal of Computer \& Mathematical Sciences.4, 13-16.

3. Vatsal, N, Patel., Arshdeep Singh., parth Gheewal., Tirth, N, Thakkar., Dhairya Bhatt. 2016. Experimental Study of Mechanical and Durability Properties of M30 Grade of Marble powder Based Concrete. International Journal of Scientific Engineering and Applied Sciences. 2, 1-6.

4. Shahul Hameed, M., Sekar, A.S.S. 2009. Properties of green concrete containing quarry rock dust and marble sludge powder as fine aggregate. Arpn Journal of Engineering and Applied Sciences. ISSN 1819-6608.

5. Patil, B.B., Kumbhar, P.D. 2012. Strength and Durability Properties of High Performance Concrete incorporating High Reactivity Metakaolin. International Journal of Modern Engineering Research. 2, 1099-1104.

6. Mohamed, M., Rashwan., Abdel RahmanMegahed., Mohamed Sayed Essa. 2015. Effect Of Local Metakaolin On Properties Of Concrete And Its Sulphuric Acid Resistance.Journal of Engineering Sciences. 43, 183-199.

7. Beulah,M., Prahallada, M.C. 2012. Effect Of Replacement Of Cement By Metakalion On The Properties Of High Performance Concrete Subjected To Hydrochloric Acid Attack. International Journal of Engineering Research and Applications. 2, 033-038.

8. ViswanadhaVarma,D., Rama Rao, G. V. 2014. Effect Of Replacement Of Cement By Metakaolin On The Properties Of High Performance Concrete Subjected To Acid Attack. International Journal of Civil, Structural, Environmental and Infrastructure EngineeringResearch and Development. 4, 63-72.

9. Gruber, K.A., Terry Ramlochan, Andrea Boddy, Hooton, R.D., Thomas, M.D.A. 2001. Increasing Concrete Durability with High-Reactivity Metakaolin. Cement and Concrete Composites. 23, 479-484.

10. Naik, T. R., Patel V.M., Parikh D. M., Tharaniyil M.P. 1996. Application of foundary by-product materials in manufacture of concrete and masonry products.ACI materials Journal.

11. Han-Young Moon, Yun-Wang Choi, Youg-Kyu Song and Jung-Kyu Jeon. 2005. Fundamental properties of Mortar and Concrete using waste foundry sand. Journal of the Korea Concrete Institute. 17, 141-147.

12. Rafat Siddique, Geert de Schutter, Albert Noumowe. 2009. Effect of used-foundry sand on the mechanical properties of concrete. Construction and Building Materials. 23, 976-980.

13. Saveira Monosi, Daniela Sani \& Francesca Tittarelli. 2010. Used foundry sand in cement mortars and concrete production. The open waste management Journal, 18-25.

14. Khatib J. M., Baig S., Bougara A., \& Booth C. Foundry sand utilization in concrete production. Second International Conference on Sustainable Construction Materials and Technologies. ISBN 978-1-4507-1490-7.

15. Kumbhar P. D. and Usharani S. Sangar. 2011. Experimental study of mechanical properties of concrete blended with used foundry sand. Global Journal Engineering and Applied Sciences. 122-126.

16. L Da Silva W.R., Tochetto E., Prudencio L.R. \& Oliveira A.L. 2011. Influence of foundry sand residues on the fresh and hardened properties of mortars produced with Portland cement. Ibracon Structures and Materials Journal. 4, 642662.

17. Mathiraja, C. 2013. Mechanical Properties of concrete using bottom ash and M.Sand. International Journal of Latest Trends in Engineering and Technology.

18. DurgaDevi, S., Chandrasekaran, P. 2015. Mechanical and Durability Properties of waste foundry sand concrete with carbon Fibers. International Journal of Science and Engineering Research.

19. Khatib J.M., Herki B.A., Kenai S. 2013. Capillarity of concrete incorporating waste foundry sand. Construction and Building Materials. 47, 867-871.

20. Eknath P., Salokhe, Desai, D. B. Application of foundry waste sand in manufacture of concrete. IOSR-JMCE, ISSN: 2278-1684, 43-48.

21. Rafat Siddique, Gurpreet Singh, Rafik Belarbi, Karim Ait-Mokhtar, Kunal. 2015. Comparative investigation on the influence of spent foundry sand as partial replacement of fine aggregates on the properties of two grades of concrete. Construction and Building Materials. 83, 216-222

22. Gurpreet Singh, Rafat Siddique. 2012. Abrasion resistance and strength properties of concrete containing waste foundry sand (WFS). Construction and Building Materials. 1, 421-426. 
23. Gurpreet Singh, Rafat Siddique. 2012. Effect of waste foundry sand (WFS) as partial replacement of sand on the strength, ultrasonic pulse velocity and permeability of concrete. Construction and Building Materials. 26, 416-422.

24. IS: 10262: 2009.Concrete Mix Proportioning - Guidelines. Bureau of Indian Standards. New Delhi. India.

25. IS: 12269: 1987. Ordinary Portland Cement, 53 Grade — Specification.Bureau of Indian Standards. New Delhi. India.

26. IS 383:1978. Specification for Coarse and Fine Aggregates from Natural Sources for Concrete. BIS. New Delhi. India.

27. IS516:2004. Methods of Tests on Strength of Concrete. Bureau of Indian Standards. New Delhi. India. 